\title{
Strategic Planning Process and Organizational Structure: Impacts, Confluence and Similarities
}

\author{
Dyogo Felype Neis ${ }^{\dagger}$ \\ Universidade Federal de Santa Catarina \\ Maurício Fernandes Pereira ${ }^{\Omega}$ \\ Universidade Federal de Santa Catarina \\ Emerson Antonio Maccari ${ }^{¥}$ \\ Universidade Nove de Julho
}

\section{ABSTRACT}

This article aims to analyze the relationship between the strategic planning process and organizational structure in the reality of a complex organization: the Public Prosecutor's Office of Santa Catarina (MPSC). The research is set by the single case study research strategy and data were collected through the following instruments: bibliographical research, documentary research, semi-structured interviews and systematic observation. The conclusion indicates that the phases of the strategic planning process influence and are influenced by the elements of the organizational structure and highlights the confluences, the impacts and similarities between the stages of formulation and implementation of the strategic process with the various constituent elements of the organizational structure.

Keywords: Strategic planning; Formulation; Implementation; Organizational structure.

\section{INTRODUCTION}

The Management Tools and trends 2015, a research conducted by Bain \& Company consultants, once again demonstrates that the strategic planning process is one of the most used management tools and has one of the highest rates of satisfaction in relation to other tools (RIGBY; BILODEAU, 2015). However, like any organizational tool, the strategic planning process has received a lot of criticism over time, among them is the difficulty in implementing strategies due to the separation between formulation and implementation of strategy (MINTZBERG, 1994).

After conducting research in scientific studies database, we identified that, compared to the formulation process, there are few studies aimed at understanding the implementation of strategies generated from the strategic planning process, especially in the Brazilian context. Kich and Pereira (2011) contribute to this prerogative when they claim that more attention is given, both by the authors from the area as by executives, in the formulation phase of the strategic planning process, neglecting its implementation. In this sense, Jick (2001) conceives that since the beginning of the development of studies on strategy researchers focus their efforts on understanding the formulation, but forget that without the full implementation of planned actions, all this effort does not generate
Corresponding author:

† Universidade Federal de Santa Catarina

E-mail: dyogoneis@hotmail.com

$\Omega$ Universidade Federal de Santa Catarina

E-mail:mfpcris@gmail.com

${ }^{¥}$ Universidade Nove de Julho

E-mail: emersonmaccari@gmail.com

Received: 02/01/2016.

Revised: 04/21/2016.

Accepted: 04/26/2016.

Published Online: 12/01/2016. 
any practical result. The imbalance between excessive attention in the strategy development process and a relative precariousness in the implementation process, both in literature and in the practice of organizations, comprise the focus of analysis of this research.

The few studies that focus on the implementation of strategies have emerge over recent years, and this shows that the interest of researchers in understanding this process is relatively recent. Studies conducted by Beer and Eisenstat (2000), Hrebiniak (2006), Brenes, Mena and Molina (2008), Galan and Sanchez-Bueno (2009), Spee and Jarzabkowski (2009), Amitabh and Gupta (2010), Kich and Pereira (2011) and Neis et. al. (2015) indicate that the strategies formulated from the strategic planning process need to be aligned with the organizational structure to be effectively implemented.

While some authors state that structure follows strategy (CHANDLER, 1962; HOMBURG; KROHMER; WORKMAN, 2004; HREBINIAK, 2006), others show that the organizational structure is what defines the strategy (HALL, 2004; CERTO; PETER, 2005). There are also studies which conclude that the structure and strategy influence reciprocally in the organizational environment (BRENES; MENA; MOLINA, 2008; GALAN; SANCHEZ-BUENO, 2009; AMITABH; GUPTA, 2010; KICH; PEREIRA, 2011).

This relationship is even more pronounced when the strategies are generated from the strategic planning process, since the tool itself tends to restrict the flexibility of internal processes, which is precisely one of the criticisms of the organizational tool in question (POISTER, 2010). Given that the organizational structure corresponds to the total amount of ways in which the work is divided into several tasks and how they are coordinated (MINTZBERG, 2008), the organizational structure must be suitable to the environment which it is inserted in (VOLBERDA, 1998, 2004; SUAREZ; CUSUMANO; FINE, 1995).

With an increasingly unstable environment, it is possible to identify the emergence of new configurations of practices in organizations, as the composition of teams, the flattening of the hierarchy, the use of the multi-functionality of employees and the use of flexible technologies. The more dynamic the environment is, the more organic the organizational structure should be. Therefore, this may be a continuum between mechanical and organic, which corresponds to the potential of a structural flexibility that the organization has (VOLBERDA, 1998; MINTZBERG, 2008).

Thus, this article aims to evolve with the discussions on the relationship between strategy and organizational structure from a complex case: the Public Prosecutor's Office of Santa Catarina (MPSC). The definition of the case was grounded on three basic premises: the institution is in the implementation phase of the strategic planning process, it has a complex organizational structure and is part of the Brazilian public context. Based on MPSC particularities, we expected that the defined event can contribute to the understanding of the strategy-structure relationship.

Given the above, the question to be answered by the research effort is: How does the relationship between the strategic planning process and the organizational structure in the MPSC occur?

\section{THEORETICAL FRAMEWORK}

The discussion on the relationship between strategy and structure is far from reaching a consensus. From Alfred Chandler's work, Strategy and Structure, with its first version published in 1962 and still widely discussed over the literature in its field, the author states that the organizational strategy determines its structure (GALAN; SANCHEZBUENO, 2009). Chandler (1962) conceives that companies are managed by inertia, 
BBR

14,5

481

they only alter its orientation or strategy when they are forced by competitive pressure. The author also states that the success of these strategic changes depends directly on the decisive changes in the organizational structure. It is in this context that the author renders his remarkable statement: structure follows strategy. At the time, this thesis showed consistency from the structural changes introduced by the competitiveness of the automotive sector, captained mainly by the assembly line of Ford and GM. The relation of cause and effect between strategy and structure is visible in organizations that adopt the strategy of vertical integration, because from the moment that the company takes responsibility in new stages of the production process, for example, the requirement of adequacy of its organizational structure created.

Driven by these findings, the interest in the subject has increased over the years. The relationship between strategy and structure remains present, even after more than five decades of discussions, however, current studies focus on identifying which construct actually influences and which is influenced and to investigate how these influences occur (GALAN; SANCHEZ-BUENO, 2009).

In this context, Homburg, Krohmer and Workman (2004) agree with Chandler. As also exposed by Hrebiniak (2006), the authors describe that based on a sequential model, organizations decide the strategy and subsequently, analyze how they will adapt organizational settings, with the organizational structure among these.

In contrast, based on the analysis of the relationship between structure, strategy and performance, Amitabh and Gupta (2010) state that the structure is considered one of the key factors for the implementation of a successful strategy, largely because performance is directly influenced by how the activities of an organization are structured. In this same line of reasoning, the research conclusion by Brenes, Mena and Molina (2008) identifies that the implementation of a successful strategy is directly related to the alignment between strategy, structure and organizational culture. As for the elements of the structure that impact the successful implementation of the strategy, the researchers highlight the potential of decentralization, primarily related to the delegation of decision making at lower hierarchical levels, in addition to the effective relationship between internal processes and work systems.

In addition, the structure was identified by Hussey (1996), Hrebiniak (2006) and Pereira (2010) as an essential factor for organizational strategy implementation. The authors agree that the structure must be aligned with the strategy, as well as providing coordination, information sharing and clearly define the responsibility of each member. the organization's culture is what enables for a strategic planning process to work $[\ldots]$;a coherent organizational structure with the organization's characteristics and the chosen planning model; the abilities, the talents and the level of knowledge of those who are at the forefront of the process; a leadership strong and capable enough in order to stimulate and influence when required; and procedures, and efficient and effective mechanisms always with future results in sight (PEREIRA, 2010, p. 64).

Hall (2004) states that from the moment that the structure determines the distribution of power, the division of hierarchical levels, the relations of internal processes and especially the division of work, it is the structure that leads the strategy, precisely because it is the structure that establishes who will participate in the formulation and strategic implementation. In cases where there is no formalization of the strategy, this relationship is more pronounced, since the strategies tend to be generated by emerging processes (KICH; PEREIRA, 2011).

There seems to be no doubt that there is a very close relationship between structure and strategy. However, there is still no paradigm formed, let alone a consensus on the subject. Some researchers conceive that the strategy transforms and determines 
the structure, whilst others proffer that the structure conceives the basic guidelines of the strategy. But after all, how do the strategies generated from the planning process influence or are influenced by the organizational structure? To answer this question, it is necessary to comprehend the understanding of agents that discuss this topic in the literature.

For over thirty years, Ackoff (1982) claimed that the strategic planning process impacts the organizational structure to the point of generating the need for system reorganization. The author also complements, that to accept the limitations of structure in the process of implementation can deprive the organization to benefit from the main advantages of this process, among which are the improvement of formal and informal interactions, decision-making process and decentralization, mainly due to increased autonomy and commitment from the moment in which an organization has a clear path to follow.

In this sense, Hrebiniak (2006) also states that the strategic planning process directly impacts the structure, given that it determines the interdependence between the various parts that make up the organization, in addition to distinguishing the functions and the individuals who must work in the same objective. Thus, the strategy defines the methods of coordination and integration necessary for the performance of activities which, in turn, it is the basic characteristic of the organizational structure. According to the respondents in the author's research

the structure is often established or altered for the wrong reasons. Planning efforts or re-planning are misguided and, often, are frustrating or are doomed to failure. The integration and coordination of different structural units is deficient or incomplete. The connection with the strategy during changes in the structure is not very clear or, often it is simply non-existent (HREBINIAK, 2006, p. 115).

This demonstrates the importance of coordination and integration of the various units, precisely where the strategic planning process is able to contribute. In this context, studies by Spee and Jarzabkowski (2009) proved that the implementation of the strategic planning process can relate the various organizational units. The interconnection driven by the strategic planning process is of paramount importance to facilitate the social interactions of a company, which in turn have the power to facilitate the practice and implementation of strategies. We know that for the successful implementation of the strategy it needs to be recognized and legitimized by several members and stakeholders comprising the organization, and through these interactions it is possible to even move through the boundaries of departments or units, through the distribution of hierarchical power and the division of tasks and units.

In contrast, Hall (2004) advocates that the organizational structure is what defines the strategy. The author contradicts the concept of the classical approach proposed by Whittington (2002) based on the understanding that, in most cases, individuals involved in the strategic planning process comprise the high organization's senior management. Thus, individuals who are in power from the configuration of the structure are who formulate the strategies. In this case, it is important to emphasize the possible ways to compose the team of strategic formulation according to the methodology by Pereira (2010), namely: top-down, botton-up and mixed. Especially in the first way to compose the team, the conception by Hall (2004) makes perfect sense. Based on the principle that the structure determines the hierarchical levels, the decision-making level and where and which strategic activities are exercised, the structure has a direct impact on organizational strategies.

Certo and Peter (2005) conceive that any change in an organization structure has an impact on the strategy. Thus, it is necessary to acknowledge the likely impact of the 
structure on the implementation of the strategy. In accordance with the design by Hall (2004), the authors also state that the definition of those responsible for strategic actions, and even the definition of the monitoring team is based on the structure. However, Certo and Peter (2005) disagree with one of the issues raised by Hall (2004) when they advocate the creation of a Strategic Business Unit upon implementation of the strategic planning process, which configures more of an influence strategy in the structure. On one hand, this unit can contribute to the process of strategic implementation, especially in coordinating and integrating the various units related to each strategic action. On the other hand, from the moment that this new unit enters another hierarchical level, it can limit the speed of the decision-making flow and delay the process of strategic implementation, primarily due to centralization of the decision-making process.

On this matter, it is worth mentioning that Pereira (2010) suggests the composition of the Monitoring and Control Team. The author argues that the team should consist of employees who have actively participated in the strategic formulation stage and that have representatives from all organizational levels. Therefore, the responsibility is shared by all, increasing motivation, participation and the autonomy of all the components of this team. The prerogative by Pereira (2010) is similar to the research results by Beer and Eisenstat (2000), which identified six factors that directly interfere with the failure of the implementation of strategies resulting from the strategic planning process. Among these factors we find the top-down management style, the lack of development of the skills of the lower hierarchical levels and inadequate coordination between the tasks, units and divisions of the organization.

Regarding the relationship between the strategic planning process, it is also worth noting the research by Kich and Pereira (2011). The authors concluded that the structure influenced the strategic planning process, since most of the decisions are made by individuals comprising the senior management, just as it was influenced, in view of creating a department that is solely responsible for the strategic issues of the organization. Moreover, the process increased the integration between sectors, mainly due to the pursuit the same objectives.

Given the above, it is clear that there is a constant and reciprocal relationship between strategy and organizational structure. In particular cases, the structure models the strategy, and at other times the strategy determines the organizational structure. However, there are few studies that deeply analyze in which elements there is this relation of cause-effect or of influence. This research aims precisely to address this gap, deepening the studies on the formulation and, especially the implementation of the strategies generated by the strategic planning process and its relationship comprising the organizational structure. To understand how this relationship occurs, the use of methodological procedures is essential, which is the content of the next chapter

\section{METHODOLOGICAL PROCESS}

For this research, we chose to follow the case study research strategy due to the very character of the objective itself. The research effort followed the prerogatives by Yin (2009), which states that to develop a consistent case study it is necessary to follow five steps: research outline; research design; preparation and collection of data; analysis of the cases and between the cases; and preparation of reports. Although it is not set by topics, the main activities developed in each stage are detailed in this chapter.

Based on the theoretical framework, we developed categories of analysis that supported the collection and analysis of data. These categories are divided into two constructs: strategic planning process and structure. The categories of analysis of the first construct, are based on the methodological framework by Pereira (2010) and 
relate to the formulation phase and the implementation phase of the strategic planning process. The second construct is based on the methodological framework by Volberda (1998) and refers to three sub-dimensions and their respective indicators, namely: basic organizational form; planning and control system; and regulatory processes. The definition for these references is sustained on the understanding of the consistency with the reality of both and on their research capacity.

To match the external validity, reliability and construct validity (YIN, 2009; GERRING; MCDERMOTT, 2010), we elaborated the guiding propositions of the case study based on Brenes, Mena and Molina (2008), Galaz Sanchez-Bueno (2009), Amitabh and Gupta (2010) and Kich and Pereira (2011), namely: (1) the formulation of the strategic planning process influences and is influenced by elements of the organizational structure; (2) the implementation of the strategic planning process influences and is influenced by elements that comprise the organizational structure.

After defining the research proposals, we defined the case to be analyzed, which followed a basic assumption: to be in the implementation phase of the strategic planning process. Given the research objectives, this was the starting point for the definition of case, because the other research construct is a factor that composes the environment of any organization, albeit it may not be formally defined. Moreover, the choice of the MPSC further gains consistency due to the following factors: its organizational structure is considered a professional bureaucracy (MINTZBERG, 2008), as it has similar activities (Prosecutors and Justice Prosecutors feature functional independence) and support activities (civil servants) clearly defined; its organizational structure is regulated by Law $n^{\circ} 8.625 / 1993$, termed as the Public Prosecutor's Office National Organic Law , requiring that changes in the structure must be approved by the State Legislative Power (MPSC, 2014); the institution made free access to research-related data available to researchers.

Therefore, we developed the research protocol that guided the researchers through data collection from the prior clarification of the general assumptions which should be followed in the field of work, as indeed it occurred. In addition to the data collection tools, this protocol determines the rules and procedures followed before, during and after collection (YIN, 2009). The research's main source was the semi-structured interview, besides the use of bibliographic research, documentary research and systematic observation. Among the analyzed documents and records of the MPSC, we highlight: Prosecutor's Guide of Santa Catarina; Organization Chart; Public Prosecutor's Office National Organic Law $n^{\circ}$ 8.625; Strategic Planning MP 2000; Strategic planning of the Public Prosecutor's Office of Santa Catarina 2004-2009; Strategic Planning MPSC 2012-2022; Monitoring Reports of the Strategic Planning Formulation MPSC $2012-$ 2022; General Plan of Action 2013; Institutional Management Report 2012; Research - Perception of the state population regarding the Public Prosecutor's Office of Santa Catarina; MPSC's website; 1website of the Federal Public Prosecutor's Office.

After the bibliographical and documentary research, we conducted interviews with research subjects, that were intentionally defined considering the objective of the research. The perspective of the formal ruling coalition was understood from the interviews with the Justice's Attorney-General, with the Justice Assistant Attorney General for Administrative Affairs, with the Secretary-General of the Public Prosecutor's Office, with the General Coordinator of the Operational Support Centers and the Comptroller General of the Public Prosecutor's Office. The assumptions related to the servers were based on interviews with the Administrative Coordinator-General, with the Planning Coordinator and with the Information Manager and Projects. We also interview a Public Prosecutor and a senior Public Prosecutor who currently play the role of running the MPSC. 
BBR

The survey also included the use of systematic observation in primary data collection, used primarily in the participation as a listener, in meetings of the Strategic Planning Committee. Although we did not participate in the discussions, we identified certain behaviors or environmental conditions that contributed to the study.

The collection of data in different databases and with individuals from different hierarchical levels was important for the achievement of the construct validity criteria (YIN, 2009; GERRING; MCDERMOTT, 2010), mainly due to the triangulation of data (AMIS; SILK, 2008; YIN, 2009).

After transcribing the interviews and data analysis, We sought to identify the passages or images that were related to the categories of analysis throughout the case study database (BARDIN, 1977). Thus, we began the process of content analysis by using Atlas.ti software for support, used as a complementary way to improve data analysis.

This process enabled the development of eighty-eight categories of analysis and more than four hundred and forty quotes, which together help in the understanding of the relationship between the strategic planning process and organizational structure.

It is worth noting that to analyze the relationship between the two constructs it was necessary to understand in depth the strategic process developed in the MPSC and the institution's organizational structure. After this understanding we could identify how the formulation phase and the process implementation phase influenced or were influenced by the indicators that constitute the organizational structure, this content will be discussed in the next chapter.

\section{DATA ANALYSIS}

There seems no doubt that the structure somehow interferes with the strategy and vice versa (BRENES; MENA; MOLINA, 2008; GALAN; SANCHEZ-BUENO, 2009; AMITABH; GUPTA, 2010; KICH; PEREIRA, 2011), but after all, what elements of the organizational structure are influenced by and which influence the strategic process? This research seeks to answer this question from the understanding that the strategic planning process is divided into two phases: the stage of formulating the strategies and the phase of implementing them (PEREIRA, 2010). And the organizational structure consists of a series of widely discussed indicators in the literature (MINTZBERG; QUINN, 2001; GHOSHAL; GRATTON, 2002; HALL, 2004; MINTZBERG, 2008) and that make up the three sub-dimensions conceived by Volberda (1998), namely:

a) basic organizational form: grouping, hierarchical levels and functionalization;

b) planning and control system: regulation of objectives and priority setting, internal programming planning and progress tracking and evaluation;

c) regulatory processes: the task (amplitude, depth and interchangeability), behavior (standardization, formalization and training and education), mutual adjustments (contact devices and horizontal decentralization) and decision making (delegation and participation).

The MPSC has formulated its strategic planning process in 2012 and is in the effort to implement it. An external consultant conducted the formulation phase and most of the activities undertaken at this stage follows what is exposed in the literature, as the definition of values (SCOTT; JAFFE; TOBE, 1993; PEREIRA, 2010), the mission, vision (COLLIS; PORRAS, 1996), the analysis of the internal environment, stakeholders and the external environment (ALMEIDA, 2003; PEREIRA, 2010), the development of SWOT Matrix (PEREIRA, 2010), the development of strategic matters, strategies and strategic actions and heightening awareness that permeates this entire process (DYE; SIBONY, 2007; PEREIRA, 2010). 
The implementation of the strategic planning process however, is being conducted by the administrative staff of the MPSC. In summary, the monitoring and control of these strategies takes place with the help of the Balanced Scorecard, which follows the same logic as formulated strategies, i.e., each strategic objective is broken down into programs, projects and actions. In most cases, each program or project has an indicator, and the actions related to these programs or projects have execution schedules. These data are regularly assessed by the Strategic Planning Committee. To sensitize the servers and especially the members is one of the main challenges of the Strategic Planning MPSC 2012-2022. The lack of commitment of members to the strategic process, primarily as a result of functional independence, was one of the research findings that should be highlighted. This legal prerogative grants Public Prosecutors and Attorneys the autonomy to act in their judicial enforcement activities. However, it is worth noting that even with this challenge, the Institute has been working on the implementation of the process and achieving positive results.

To analyze the organizational structure of the MPSC, we used the methodological framework by Volberda (1998). All the indicators comprising the sub-dimensions designed by the author were employed to analyze it. Functional independence also influences the elements of organizational structure and makes it even more complex. Precisely in this scenario, the evaluation of the institution's organizational structure occurred the end and middle activity. The end activity refers to the execution itself and is under the charge of the Public Prosecutors and Attorneys, whereas the middle activity concerns the tasks that are not necessarily related to legal issues.

In this sense, the organizational structure of the end activity of the MPSC has predominantly high potential for flexibility, and grouping by target market, regulation of the objectives and setting of rudimentary priorities, the complex depth of the task, high interchangeability, low formalization of behavior, training and education of the artificer, the natural form of contact devices, high horizontal decentralization and high participation in decision-making indicate the organicism of the corresponding organizational structure to the end activity. On the other hand, the organizational structure related to the middle activity basically has mechanical characteristics. The functional clustering, the number of hierarchical levels, high functionalization, the detailing of the internal planning programming, the resolution of the progress control and evaluation, the narrow amplitude and depth of the task, the high standardization of behavior, the low horizontal decentralization and low delegation in decision making are evidence of the low potential of structural flexibility of the institution regarding middle the activity (VOLBERDA, 1998; HALL, 2004; MINTZBERG, 2008).

Based on this understanding, we evaluated the relationship between the formulation and implementation phases of the strategic planning process with the elements of the organizational structure. Thus, the analysis is presented in three sections: design and implementation versus basic organizational form; formulation and implementation versus planning and control system; and formulation and implementation versus regulatory processes.

\subsection{FORMULATION AND IMPLEMENTATION VERSUS BASIC ORGANIZATIONAL FORM}

If on one hand the case of the MPSC demonstrates no proximity between the formulation of strategic planning and the grouping of basic organizational form, on the other it is possible to identify that the hierarchical levels interfere directly in this phase. Initially, the process is impacted by hierarchical levels mainly due to the process being developed based on an existing structure (HALL, 2004). Furthermore, as the 
hierarchical level itself defines the highest formal dominant coalition, which is precisely who decides to develop or not the strategic planning process, this relationship becomes even more evident (PEREIRA, 2010). Also, considering that the process of formulation may involve all employees of the organization or distinguish those who participate based on hierarchical levels logically depending on how the team is composed - and it fits therefore the definition of the formal dominant coalition -, it appears that the trend is that the levels of the organizational structure directly influence the formulation phase (HALL, 2004; KICH; PEREIRA, 2011).

The formulation phase is also impacted by the functionalization of the basic organizational form, and some research findings are worth mentioning. The main finding of this relationship assumes that the formulation of the strategic planning process may be impacted as the participants in the process become more concerned with their specific function or their own area than with the organization as a whole, which Ranson, Hinings and Greenwood (1980) recognize as departmentalization. The possibility of this influence is also due to the fact that the formulation is made from an organizational structure that establishes organizational guidelines. Especially in organizations characterized by high functionalization of the basic organizational form, as is the case of the MPSC, the strategic planning process tends to contribute more evidently, given that the process enables the strategic guidelines to be formulated with the participation of all areas and functions, consequently, it increases the organizational viewpoint at the expense of departmental one.

So far, the relation between the elements of the basic organizational form and the formulation phase of the strategic planning process is basically cause and effect. But this logic is reversed when dealing with the implementation phase, especially because the objective formulation is to understand the internal and external environment of the organization and define the strategic guidelines, however these settings usually will only be put into practice during the implementation phase (HREBINIAK, 2006; PEREIRA, 2010). In this context, the implementation impacts all elements of the basic organizational form.

Initially, the implementation impacts the grouping from the moment the areas begin to work together and in partnership in the pursuit of a broader organizational objective than the objective of one particular area, i.e., the strategic planning process unites the sectors (KICH; PEREIRA, 2011). This phenomenon tends to change the grouping of the Institution, because the division can extrapolate the functional form and boost the grouping focused on a product or even target market, which sets greater potential for flexibility. In addition, changes in organizational structure resulting from the process tend to impact indirectly in the grouping, since this element is directly related to the hierarchical levels and the organization of functionalization.

Regarding the relationship between the implementation phase and hierarchical levels, we note the existence of a reciprocal relationship. On the one hand, the implementation of the strategic planning process propels changes in the organizational structure, which can be characterized by the formation of new positions, departments, agencies, sectors and even the exclusion or modification of internal structures. On the other, the hierarchical levels also impact the implementation phase from the moment these changes are infeasible and ultimately limit the execution of a particular strategic action. In addition, in accordance to what we identified in the case study Kich and Pereira (2011), the commitment to the implementation of the process begins by the most formal dominant coalition of the organization and are precisely the hierarchical levels that formalize the institution's chief figure.

The implementation phase interferes with the functioning of the basic organizational form to the extent that the strategic planning process indicates changes in the organizational 
structure, and that operation is dependent, even if indirectly, of hierarchical levels, since the greater the number of hierarchical levels and side departments, the greater will the functionalization level of the structure tend to be (VOLBERDA, 1998). Also, from the moment in which the areas are joined in the search for a target, as a result of the process, the functionalization tends to have greater flexibility potential, this shows that the implementation influences the functionalization.

Therefore, the formulation phase of the strategic planning process is impacted by the elements of the basic organizational form, while the implementation primarily impacts the grouping, hierarchical levels and the organization of functionalization.

\subsection{FORMULATION AND IMPLEMENTATION VERSUS PLANNING AND CONTROL SYSTEM}

The indicators of this sub-dimension are so close to the formulation and implementation phases of the strategic planning process which in some instances both constructs virtually unite in a unique understanding, because certain indicators aim to precisely assess how organizational goals are set and monitored, corresponding respectively to the formulation and implementation of the process phases.

The setting of objectives and priority setting has close ties with the formulation phase of the strategic planning process, for it is known that the definition of objectives in the MPSC is precisely through this process. In fact, the Code Cooccurrence Table, a report generated by the Atlas.ti from the research data, demonstrates that in most cases the research subjects addressed the analysis category "Formulation", also reported the analysis category "Regulation of Objectives and priority setting", which shows the similarity between these two elements.

In addition, the internal programming planning in the case of the institution derives from the Strategic Planning MPSC 2012-2022, primarily due to this process unfolding the strategic objectives and strategic initiatives, which in turn are detailed in programs and projects, which may be further specified in strategic actions. This element of the planning and control system relates both to the phase of formulation and to the implementation phase. With regards to formulation, the relation occurs by establishing how all these events should take place. Regarding the implementation however, the internal programming planning is configured from the actual implementation of the objectives, initiatives and strategic actions.

Just as the regulation of objectives and priority setting are associated with the formulation phase, progress evaluation and control relates to the implementation of the process, as also indicated in the Code Cooccurrence Table report. In organizations that use strategic planning process, such as the MPSC, it is common for the control and the evaluation to result from the monitoring of the implementation of formulated actions in the process. Therefore, it appears that there is no cause and effect relationship, but rather a certain similarity.

And actually, the trend is that this approach would lead to the conclusion that the relationship between the organizational structure and strategy, in its broadest sense, to really be reciprocal, so much so that the very methodological framework by Volberda (1998) encompasses the formulation phase and implementation of organizational strategies. In this sense, where the strategy results from a deliberate process analysis, the planning and control system tends to be considered as prepared. In contrast, in organizations that use the emerging strategic process to form their strategies, the tendency is for this sub-dimension to be analyzed from the rudimentary character. 


\subsection{FORMULATION AND IMPLEMENTATION PROCESSES VERSUS REGULATION}

Unlike the relationship between the formulation phase and the basic organizational form, this phase of the strategic planning process interferes directly in regulatory processes comprising the organizational structure. Especially in regard to the regulation of mutual adjustments and decision making, this phase has more of an impact rather than suffering one.

It is noted that the regulation of mutual adjustments is influenced by the formulation of the strategic planning process from the moment that this process enables all employees to participate in the formulation of strategic guidelines, regardless of area of operation, function and hierarchical level. This discussion tends to increase informal communication between staff and decentralize the activities of departments, which increases the potential for flexibility of the contact devices and the horizontal decentralization.

Also as a result of the participation of all employees, the delegation and participation in the decision-making process increases during the formulation phase. It is also worth noting that, as the organizational structure itself defines the formal dominant coalition, it ends up interfering in this process, given that it is outlining the basic characteristics of the strategic planning process, and how to compose the formulation team is among them.

Regarding the implementation of the process, the tendency is that the regulation processes are further impacted. For example, the implementation impacts the regulation of tasks in that the formal organizational structure tends to be altered by the strategic planning process, either through the creation of new positions, or even by the change in the operation of certain departments. Just as the functionalization of the basic organizational form is affected, the amplitude and depth of the jobs are indirectly changed from the adjustments in the organization chart.

In contrast, with respect to training and education, implementation both causes an impact as it suffers one. The trend is for the strategic planning process to interfere in this matter when the training ends up being performed based on formulated objectives, as could be seen in the reality of the MPSC. However, the implementation ends up being impacted from the moment that knowledge is acquired by employees through these courses it then contributes to the achievement of strategic objectives and even for the improvement of their own strategic planning process, even when referring to appropriate changes in organizational culture (BEPPLER; PEREIRA, 2013).

The implementation also impacts the decision-making regulation, especially from the moment the participation and delegation of employees increases due to the implementation of strategic actions previously formulated. In the reality of the MPSC, the delegation becomes more difficult because of the legality of power which the position the Public Attorney-General has. However, changes in the structure resulting from the strategic planning process tend to change the delegation and participation in the decision-making process, as was the case of the creation of the CoordinationGeneral for the Operational Support Centers and the Public Assistant Attorney-General for Administrative Affairs. This decision increased participation in decision-making process, despite not being legally able to replace the Public Attorney-General in the decisions referred exclusively to the position of Chief of Institution. Moreover, the openness to the participation and delegation in the decision-making process depends on the leader's profile, therefore, considering it is the organizational structure that determines the most formal dominant coalition, logically that all this regulation is impacted by this construct. 


\section{CONCLUSION}

This research aimed to evaluate the relationship between the strategic planning process and organizational structure. After understanding the strategic process and organizational structure of the MPSC, we identified how the stages of formulation and implementation of the strategic planning process influence or are influenced by elements of the organizational structure in the reality of the MPSC. To achieve this goal, we chose the case study research strategy, which was outlined on the basis of the methodological framework by Yin (2009).

From the identification of the relationships between the elements of the organizational structure and the phases of the strategic planning process, we concluded that the two propositions are confirmed. Proposition 1 conceives that the formulation of the strategic planning process influences and is influenced by elements of the organizational structure, whereas Proposition 2 considered that the implementation of the strategic planning process influences and is influenced by elements of the organizational structure.

Some elements of the organizational structure impact the stages of the process, others are impacted. Some interfere more, some less. Some have reciprocal relations, while others are so close that they can even be understood as similar. Figure 1 summarizes the relationships identified between the formulation and implementation of the strategic planning process with the elements of the organizational structure in the reality of MPSC. The relations highlighted in red which express that the relationship is of a onesided impact; in blue, there is a reciprocal relationship; and green, there is a strong correlation between the two units.

The phases of formulation and implementation of the strategic planning process have different ways of relating to the constituent elements of the organizational structure. The lines highlighted by the blue color demonstrate the relational similarities, green indicates the confluences, and red show the unilateral and reciprocal impacts. These findings corroborate the research findings by Brenes, Mena and Molina (2008), Galan and Sanchez-Bueno (2009), Amitabh and Gupta (2010) and Kich and Pereira (2011).

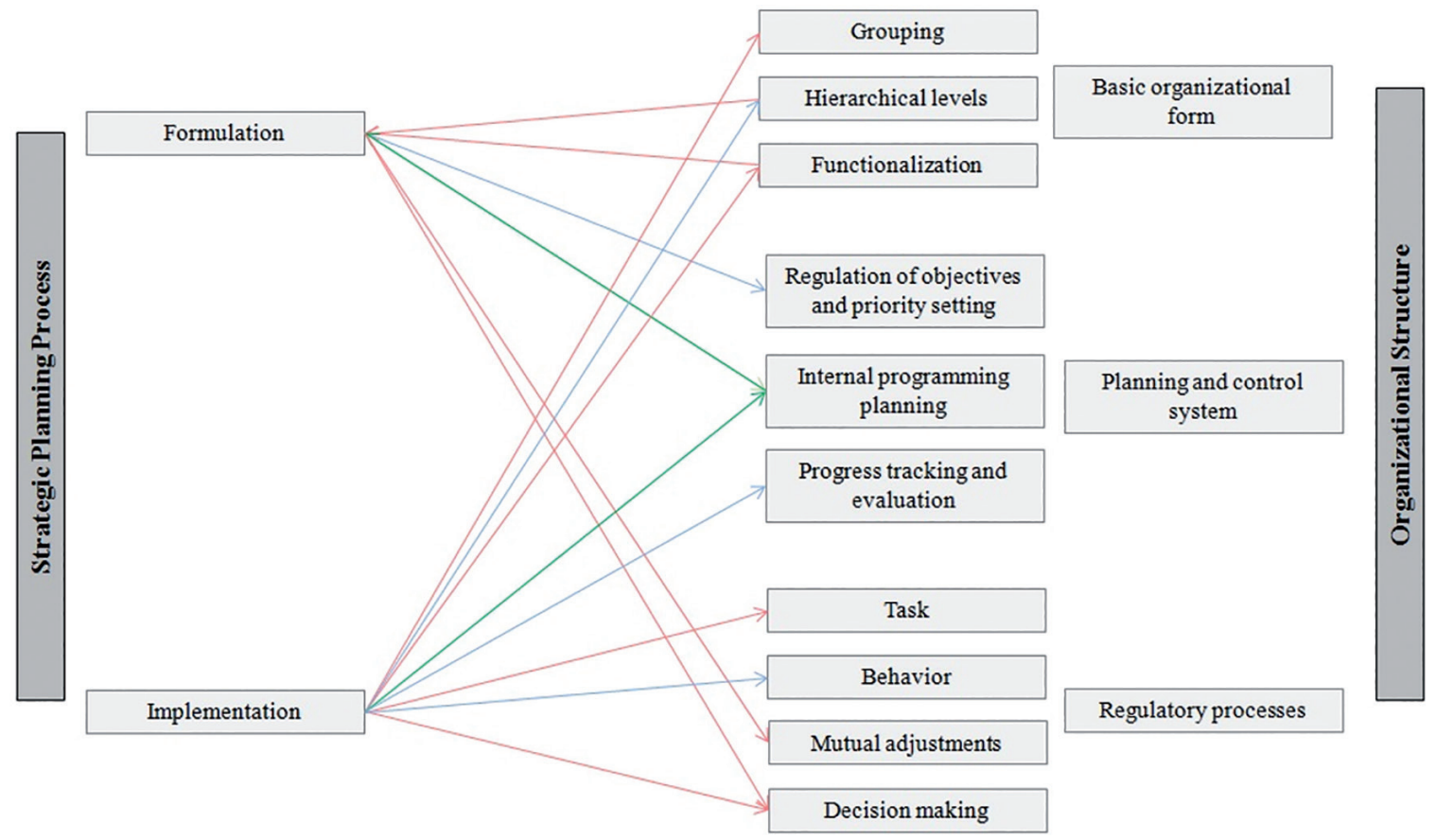

BBR

14,5

Figure 1. Phases of the strategic planning process versus elements of the organizational structure 
BBR

14,5

Therefore, this study further examined the perspective of the relationship between organizational structure and strategy, more specifically from the strategic planning process. As the main limitation of this research concerns the impossibility of generalization of the case to other organizations as it is an in depth case study, we recommend the development of other research in organizations that are also in the process of the implementation phase, seeking to observe similarities and differences of the relationship between the two constructs.

Furthermore, analyzing other organizational factors that influence the implementation of the strategic planning process is part of the scope of the evolution of knowledge on strategy. It is known that the research by Kich and Pereira (2011) identified that the implementation of the process is influenced by four organizational factors, namely: structure, culture, communication and leadership. As a result of this research, Beppler and Pereira (2013) went deeper into the theme culture and strategy, while the present study evaluated the organizational structure factor in depth. Thus, we suggested exploring the details of the relationship between the strategic planning process with the communication and the leadership, as well as other organizational factors that may hinder or facilitate the implementation of strategic planning, such as innovation.

\section{REFERENCES}

ACKOFF, R. L. Planejamento Empresarial. Rio de Janeiro: LTC - Livros técnicos e Científicos Editora S.A., 1982.

ALMEIDA, M. I. R. Manual de planejamento estratégico. São Paulo: Atlas, 2003.

AMIS, J. M.; SILK, M. L. The Philosophy and Politics of Quality in Qualitative Organizational Research. Organizational Research Methods, v.11, n.3, p.456-480, 2008.

AMITABH, M.; GUPTA, R. K. Research in strategy-structureperformance construct: Review of trends, paradigms and methodologies. Journal of Management and Organization, v. 16, n. 5, p. 757-776, 2010.

BARDIN, L. Análise de conteúdo. Lisboa: Edições 70, 1977.

BEER, M.; EISENSTAT, R. A. The silent killers of strategy implementation and learning. Sloan Management Review, v. 41, n 4, p. 29-40, Summer, 2000.

BEPPLER, M. K.; PEREIRA, M. F. Planejamento estratégico: a contribuição da cultura organizacional para o processo de implementação da estratégia. v. 3. São Paulo: Atlas, 2013.

BRENES, E.; MENA, M.; MOLINA, G. Key success factors for strategy implementation in Latin America. Journal of Business Research, n. 61, p. 590-598, 2008.

CERTO, S. C.; PETER J. P. Administração estratégica: planejamento e implantação da estratégia. $2^{\mathrm{a}}$ ed. São Paulo: Prentice Hall, 2005.

CHANDLER, A. Strategy and structure. Cambridge, Ma: MIT Press, 1962.

COLlinS, J. C.; PORRAS, J. I. Building Your Company's Vision. Harvard Business Review. SeptemberOctober, 1996.

DRUCKER, P. F. Introdução à Administração. São Paulo: Pioneira, 1977.

DYE, R.; SIBONY, O. How to improve strategic planning. Mckinsey Quarterly, v. 3, p. 40-49, 2007.

GALAN, J. I.; SANCHEZ-BUENO, M. J. The continuing validity of the strategy-structure nexus: new findings, 1993-2003. Strategic Management Journal, v. 30, n. 11, p. 1234-1243, 2009.

GERRING, J.; MCDERMOTT, R. An experimental template for case study research. American Journal of Political Science, v.51, n. 3, p. 688 - 701, 2010.

HALL, R. H. Organizações: estrutura, processos e resultados. 8a ed. São Paulo: Pearson Prentice Hall, 2004.

HAMBRICK, D. C.; FREDRICKSON, J. W. Are you sure you have strategy? Academy of Management Executive, v. 15, n. 4, p. 48-59, Nov 2001.

HOMBURG, C.; KROHMER, H.; WORKMAN, J. P. A strategy implementation perspective of market orientation. Journal of Business Research, v. 57, p. 1331-1340, 2004.

HREBINIAK, L.G. Fazendo a estratégia funcionar: o caminho para uma execução bem-sucedida. Porto Alegre: Bookman, 2006.

HUSSEY, D. The Implementation Challenge. Chichester, England: John Wiley \&Sons, 1996.

JICK, T. D. Vision is 10\%, Implementation the Rest. Business Strategy Review, London, v. 12, n. 4, p. 36-38, 2001. 
KICH, J.; PEREIRA, M. F. A influência da liderança, cultura, estrutura e comunicação organizacional no processo de implantação do planejamento estratégico. Cadernos EBAPE.BR, v. 9, nº 4, artigo 6, p. 10451065, Rio de Janeiro, 2011.

MINTZBERG, H. The Fall and Rise of Strategic Planning. Harvard Business Review, p. 107-114, 1994. . Criando organizações eficazes: estruturas em cinco configurações. $2^{\mathrm{a}}$ ed. $4^{\circ}$. reimpressão, São Paulo: Atlas, 2008.

MPSC - Ministério Público de Santa Catarina. Portal MPSC: Instituição. Disponível em: . Acesso em 12 jan. 2014.

NEIS, D.; PEREIRA, M. F.; SOARES, M. L.; GOMES FILHO, W. V. O Processo de Implementação das Estratégias: o caso do Ministério Público de Santa Catarina (MPSC). Revista de Ciências da Administração, V. 17, n. 42, p. 22-37, 2015.

PEREIRA, M. F. Planejamento estratégico: teorias, modelos e processos. São Paulo: Atlas, 2010.

POISTER, T. H. The Future of Strategic Planning in the Public Sector: Linking Strategic Management and Performance. Public Administration Review, v. 70, p. 246-254, 2010.

RANSON, S.; HININGS, B.; GREENWOOD, R. The structuring of organizational structures. Administrative Science Quarterly, v.25, n.1, p.1-17, mar. 1980.

RIGBY, D.; BILODEAU, B. Management Tools and trends 2015. Bain \& Company, 2015. Disponível em: <http://www.bain.com/Images/BAIN_BRIEF_Management_Tools_2015.pdf>. Acesso em 14 mar. 2016.

SCOTT, C. D.; JAFFE, D. T.; TOBE, G. R. Organizational vision, values and mission. Menlo Park, CA: Crisp Publications, 1993.

SPEE, A. P.; JARZABKOWSKI, P. Strategy tools as boundary objects. Strategic Organization, v. 7, p. 223-232, 2009.

SUAREZ, F. F.; CUSUMANO, M. A.; FINE, C. H. An empirical study of flexibility in manufacturing. Sloan Management Review, 1995.

VOLBERDA, H. W. Building the flexible firm: how to remain competitive. Oxford: Oxford University Press, 1998.

. Crisis in strategy: fragmentation, integration or synthesis. European Management Review, v. 1, $\mathrm{n}^{\mathrm{o}} 1$, p. 35-42, 2004.

WHitTingtON, R. O que é estratégia. São Paulo: Thomson Learning, 2002.

YIN, R. K. Case study research, design and methods. Thousand Oaks. California: Sage Publications, 2009. 